\title{
Notas de interés paleográfico y diplomático en la literatura bajomedieval
}

\author{
Blas Casado Quintanilla *
}

La lectura de algunas obras literarias y cronisticas de la Baja Edad Media, nos ha brindado la ocasión de conocer el pensamiento de don Juan Manuel y de Pero López de Ayala sobre temas como la escritura, la calificación diplomática de los documentos, el canciller y la cancilleria, el sistema de datación, los escribanos o copistas, las formas de validación documental y algunas otras curiosidades.

Ciertamente el documento en sí constituye la fuente ordinaria de la Diplomática, y sin lugar a dudas, la Paleografia, en cuanto ciencia de la escritura, tiene a aquel como punto de referencia. Pero ni el diplomatista ni el paleógrafo pueden desdeñar las aportaciones que a una y a otra disciplina, pueden brindarle el conocimiento de los textos literarios y, en especial, las crónicas. Aquellos y sobre todo estas, no son sino una forma más de transmisión documental; a veces, proporcionan noticias e información sobre los más variados aspectos, tanto sobre la naturaleza de los documentos, como sobre su forma externa. Ello es lógico porque los documentos, sirvieron de fuente de inspiración a los cronistas para la elaboración de sus relatos históricos. También la literatura, como fruto de una aprehensión muy singular del acontencer de su tiempo, puede revelarnos aspectos del documento que, de no ser por esta via, escaparian a nuestro conocimiento.

Una vez más será necesario reconocer que aparte de la intención prioritaria del autor, éste, en cada una de las líneas de la obra que escribe, deja constancia, cual fiel notario, no sólo de los acontecimientos que narra o de los hechos e ideas sobre las que reflexiona; también, de forma

\footnotetext{
* Prof. Titular. Área de Ciencias y Técnicas Historiográficas. UNED.
} 
posiblemente involuntaria, nos tramite otras noticias que, como a hombre del tiempo que le ha tocado vivir, no le son ajenas.

\section{LA ESCRITURA}

El invento de la escritura es posterior a la aparición de la lengua hablada. La escritura hace a la palabra duradera. Mientras que la palabra es de duración instantánea, lo escrito queda, "scripta manent, verba volent», y permite una comunicación diferida en el tiempo y en el espacio. La palabra es producida por un sujeto presente, en circunstancias particulares, delante y para un auditorio bien determinado y con un desarrollo temporal irreversible. La escritura escapa al tiempo y existe fuera de la presencia de su autor, no se mantiene sólo para lo que se produjo, sino que es accesible a todos aquellos que sean capaces de entender aquellos signos gráficos. En el mundo medieval, la palabra tenia mucha importancia, máxime en el medio eclesiástico a través de la predicación, mientras que la escritura era patrimonio de unos pocos.

Para López de Ayala, el invento de la escritura se debe a que «la memoria de los omes es muy flaca e non se puede acordar de todas las cosas que en el tiempo pasado acaescieron" y por esta razón "los sabios antiguos fallaron ciertas letras e arte de escribir" que sirvieron para que "las sciencias y los grandes fechos... fuesen scriptos e guardados para los omes los saber"?.

Nuestro cronista acostumbrado por oficio a leer documentos de la época precedente, documentos de los que recoge información para su obra histórica, asume la afirmación de la flaqueza de la memoria humana de la misma manera y con la misma formulación que aparece en el protocolo inicial de muchos diplomas reales y en la documentación particular. La flaqueza de la mente aumenta y hace resaltar la importancia de la escritura por la necesidad de conservar lo referente a las «ciencias y a los grandes fechos", olvida, porque no hace al caso del género literario cronistico, la gran cantidad de documentación aportada por los particulares en su quehacer diario de compraventas, intercambios y otros actos inter vivos.

Dedica una alabanza a los inventores de la escritura, al mismo tiempo que pone de manifiesto la idea de permanencia que implica la existencia

' Lopez de Ayala, Pero, Crónicas. Edición, prólogo y notas de José Luis Martin, Edit. Planeta, 1991, Prólogo, pág. 3. 
de este instrumento, largo brazo de la memoria humana, para que las generaciones posteriores puedan conocer las gestas de los grandes hombres que nos precedieron. Rinde homenaje a la más profunda de las aspiraciones humanas reflejada en cualquiera de las grandes civilizaciones, en las que los grandes héroes y sus memorables gestas, han llegado hasta nosotros a través de la escritura en inscripciones, en documentos, en escritos varios o monumentos. La escritura convierte en permanente la acción volátil del intelecto humano.

\section{VARIACIONES SOBRE LA CALIFICACIÓN DIPLOMÁTICA DE LOS DOCUMENTOS}

Sorprendente que Pero López de Ayala, que vivió toda su vida en los medios cortesanos, utilice el sustantivo de «carta» con tanto profusión y referido a cualquier tipo documental emanado de la cancilleria real. No podemos refugiarnos en la idea de ignorancia porque, sin duda, conoceria la variación existente entre los diversos documentos expedidos por tan alta institución. Cabe pensar que se sirve de este concepto, porque quiere utilizar el sustantivo al uso entre sus contemporáneos ${ }^{2}$, no vinculados directamente a la cancilleria real, para designar todos los documentos, con independencia de la solemnidad y contenido de los mismos, salvo en muy contadas ocasiones, que luego veremos.

\subsection{Las cartas}

El concepto de carta se aplica a todo aquel pergamino o papel escrito, con independencia de su contenido e independiente, también, del soporte de la escritura. La palabra carta aparece vinculada a la acción verbal de «enviar», señalando el origen real o no y el destinatario ${ }^{3}$.

\footnotetext{
Casado Quintanilla, Blas, Autenticidad documental y escribanos de Avila en la Baja Edad Media en Espacio, Tiempo y Forma, UNED, Serie ill. 4 (1989) 175-192.

${ }^{3}$ Lopez de Ayala, Pero, Op. cit., pág. 127. Donde el cronista indica que por los caballeros hablo ante el rey Ferrand Pérez de Ayala, quien dijo: "Señor, los señores que aquí estan,.. vos piden,... que vos les querades perdonar por ellos venir armados ante vos a estas vistas: e si asi vienen es por vuestra licencia e ordenamiento, según ge lo enviaste mandar por una vuestra carta,..." En la pág. 131 los Infantes de Aragón y el Conde don Enrique, que habian acampado cerca de la ciudad de Toro: "a la media noche ovieron cartas de la reyna doña Maria, madre del rey, que estava en Toro, faciendoles saber,..." En la pág. 132 son los Intantes de Aragón y don Enrique los que "enviaron sus cartas el rey...". La utilización
} 
Dentro del concepto de carta se incorporan los de «carta de creencia" " "cartas de seguro" ${ }^{5}$, y otros de similar formulación; el apellido de la carta se refiere al contenido de las mismas, y por tanto son escritos con una finalidad muy específica y señalada, distinta de aquellos que sólo reciben el calificativo de cartas. Estas englobarian el resto de documentos expedidos por la cancillería real con independencia de la solemnidad, el contenido o el destinatario.

López de Ayala en su obra Rimado de Palacio escribe con frecuencia el sustantito "cartas", con el significado que ya se ha expuesto. En cierta ocasión, quizá por imperativo de la rima, le añade una cualidad en modo alguno especifica: carta cerrada, adjetivo que podría aplicarse a todas a casi todas las cartas ${ }^{6}$.

Lo que precede no nos autoriza a pensar que López de Ayala, al generalizar su denominación, concediera poca importancia a la variación y distinción entre unos y otros tipos documentales, bien fueran reales o particulares. Con frecuencia muestra un alto concepto de la cancilleria real, destaca la importancia del título y funciones del canciller y no duda en afirmar que esta institución puede proporcionar grandes beneficios y resaltar el poder del rey. Así en la obra citada al exponer las cualidades del buen monarca, enumera, entre otros aspectos que este ha de tener en cuenta, algunas formas de comportamiento que atañen al objeto de nuestro estudio:

Nueve cosa yo fallo, con las quales tu verás el grant poder del rey en qué lo conosçerás;

genérica del concepto de carta no deberia sorprendernos puesto que a lo largo de toda la Edad Media es muy frecuente esta denominación. La sorpresa proviene de que López de Ayala, cronista del siglo XIV, cortesano, embajador, y hasta canciller de Enrique ill de Castíla, conocedor de la estructura de la cancilleria real y, sin duda, de las distinciones jurídicas existentes entre los documentos de ella emanados, no deje constancia de las mismas en su crónica. Incluso usa el mismo calificativo para los documentos expedidos por el rey y los escritos por los particulares.

${ }^{4}$ Idem, pág. 122 donde se narra cómo un grupo de caballeros del reino enviaron una delegación ante el rey don Pedro para presentarle sus quejas y "dixéronle que aquellos señores le enviaban sus cartas de creencia, las quales le presentaron luego, por las cuales les mandaban decir algunas cosas cumplideras a sus servicios".

"Idem, pág. 169 donde el conde don Enrique "envió facer su pleitesia con el rey que le diese sus cartas de seguro para pasar por el regno, que él se iría para Francia... El conde don Enrique, desque... ovo sus cartas de seguro...".

- López de Ayala, Pero, Rimado de Palacio. Edición de Germán Orduna, Edit. Clásicos Castalia. Madrid, 1987, pág. 214. "Antes que aya comido nin mesa levantada / llégale un mensajero, tráele una carta çerrada / ..." 
Si sus embaxadores enbia bien ordenados, caballeros muy buenos, doctores muy letrados, con buen apostamiento...

La segunda si veen su carta mensajera en nota bien fermosa, palabra verdadera, en buena forma escripta e con fermosa cera cerrada, bien seellada, con dia, mes e era ?

Entre las nueve recomendaciones, la primera la asigna a los embajadores, poniendo el énfasis en las cualidades personales y también en los signos externos; la segunda la dedica a lo relacionado con las cartas de presentación de aquellos. No debemos pasar por alto que quien escribe fue en varias ocasiones embajador de sus reyes y, por tanto, conocedor "in situ» de la importancia de lo que describe. El documento que en esta ocasión recibe el nombre de "carta mensajera" y que ha de portarla y presentarla el embajador ante su destinatario, ha de ser preparada y expedida conforme a unas exigencias diplomáticas destacadas por el autor. El texto, al adoptar la forma poética, limita las explicaciones y ensombrece el alcance de las palabras. Sin embargo, en ningún otro lugar de su obra hemos encontrado una exposición teórica tan detallada de las partes o cláusulas que componen un diploma real.

Nos atrevemos a proponer la explicación que sigue, pasando a prosa, y no tan buena como la suya, lo que conocemos en poesia, amparándonos en que el autor de estos versos conoce la cancilleria cortesana, la actividad diplomática y por añadidura las exigencias de la preparación y expedición de los documentos.

La expresión «nota bien fermosa» está referida a varias cláusulas del diploma. Incluiria la invocación; la intitulación con detallada enumeración de los títulos y extensión de los dominios del monarca; la dirección con expresión de todas las bondados y excelencias del destinatario de la carta mensajera, seguido de un atento saludo.

El preámbulo, donde con la solemnidad requerida, se recogerian las máximas de orden religioso, moral, hazañas bélicas victoriosas y demás apostillas, todas ellas adornadas con palabras que expresen la belleza de las cosas, bien para alagar los oidos de quien ha de escucharlas o bien para prepararle favorablemente ante la grandeza del principe cuyo emisario tienen delante.

La parte que precede del documento que nos ocupa, aunque ha de estar ajustada a la realidad, debe estar seguida de "palabra verdadera".

${ }^{7} /$ dem, págs. 237 y 238. 
Con esta expresión, el autor del texto nos sitúa en las cláusulas expositiva y dispositiva. Parece indicar sensu contrario que no siempre la verdad presidia el contenido de este tipo de documentos; de ello no debe deducirse, a nuestro entender, que se incluyeran mentiras. Estamos pensando en exageraciones en los titulos y en otras noticias encaminadas a sobrevalorar la personalidad, el prestigio y la fuerza del príncipe titular de diploma.

A todo esto hay que añadir que la carta ha de aparecer plancentera a la vista; ha de estar escrita siguiendo una forma adecuada y buscando la belleza externa. Belleza que ha de prolongarse hasta la "fermosa çera" que cierra el documento. Se detiene en destacar la importancia de la validación documente: "bien seellada», sin hacer mención alguna de la suscripción del rey, descargando toda la fuerza en el sello. No olvida la datación por el sistema al uso del: "dia, mes e era", aspecto éste del que luego nos ocuparemos.

Por su parte don Juan Manuel, hombre docto, siempre empeñado en adoctrinar a sus lectores y que se precia de buscar un selecto vocabulario, cuya producción literaria hay que situar también en el siglo xIV, emplea el concepto genérico de "carta" para referirse a los documentos. En su obra Libro de los Estados, después de dedicar elogiosas palabras para otros miembros de la corte real o señorial se detiene en la figura del canciller destacando su importancia y las responsabilidades que recaen sobre su oficio. El canciller debe «mandar fazer las cartas todas, tambien las mandaderas como las de ponimiento como las de guerra et de respuesta, e las que son para coger las rendas e los dineros de los señores, et las de los emplazamientos et la de pago; et todas las cartas que fueren de fuerça, deve tener registradas" ${ }^{8}$. Todos los documentos emanados de la cancilleria real o señorial son cartas. No importan las solemnidades paleográficas o diplomáticas, externas o internas, de los diplomas, importa la finalidad para la que han sido escritas: para mandar, para recaudar, para declarar la guerra o para cualquier otro objetivo.

Más que la exposición teórica de la preparación y expedición de los documentos de la cancilleria, importa desde nuestra óptica, la forma práctica en que Ayala presenta algunas cartas en su crónica.

El día 1 de abril de 1367, estando "el rey don Enrique» en Nájera, recibió una "carta" del príncipe de Gales, quien acompañaba con sus tropas y defendia la causa del rey Pedro I de Castilla y de León. Al dia si-

\footnotetext{
- Juan Manuel, Libro de los Estados, en Blecua, José Manuel, Don Juan Manuel, Obras Completas, Edit. Gredos, 1982, vol. I, pág. 403.
} 
guiente el rey Enrique II, dio respuesta a la carta del primogénito del rey de Inglaterra.

La disposición diplomática de sendas cartas, obedece a patrones sencillos y conocidos: la intitulación, la dirección, la notificación, la exposición, la disposición y la datación. Esta última cláusula está incompleta en ambas ocasiones; la validación no ha sido recogida por el cronista, ni en uno ni en otro diploma. Las variaciones, entre una y otra, no tienen mayor entidad; en la carta de Enrique II falta la notificación, aunque toda la cláusula expositiva no es sino una notificación y explicación de cómo se han desarrollado los acontecimientos políticos y sociales durante los últimos años en el reino de Castilla y de León, claro está, desde el punto de vista enriqueño ${ }^{9}$.

Eduardo, principe de Gales, escribe desde el real del Pedro I. Observamos cómo el diploma del inglés está redactado conforme a los usos diplomáticos de Castilla. El documento pudo muy bien ser preparado y expedido por alguno de los miembros de la cancillería del rey Pedro 1. Como era de esperar, Eduardo, autor de la carta, aparece con todos sus títulos; el destinatario es el «noble e poderoso principe don Enrique, conde de Trastamara", que no el rey de Castilla e de León. El título real se lo reserva para Pedro I.

Por el contrario, la intitulación de la respuesta, y no podia ser de otra manera, dice: «Don Enrique, por la gracia de Dios, rey de Castilla e de León".

Existen, sin embargo, sospechosas similitudes, no sólo en las cláusulas diplomáticas, sino también, en la utilización de las mismas expresiones literarias, bien referidas a unos o a otros personajes y adversarios políticos que van a entrar en combate. Las cláusulas diplomáticas están dispuestas en el mismo orden, con similar amplitud y muy parecido desarrollo, como si obedecieran a un único modelo. Esta es dificil de alcanzar porque dos personas que están a punto de entrar en combate no tienen la tranquilidad suficiente para una redacción perfecta; los usos cancillerescos, por muy semejantes que fueran, en uno y en otro reino, no pueden llegar a parecerse como una gota de agua a otra gota de agua.

Ambos diplomas parecen redactados por la misma persona. Para Eduardo, Pedro l es sel muy alto e muy poderoso principe don Pedro, rey de Castilla e de León». Para Enrique II, el hijo del primogénito rey de Inglaterra es "el muy alto e poderoso príncipe don Eduarde». Más simi-

9 Lopez de Ayala, Pero, Crónicas, págs. 348-351 
litudes, en la cláusula dispositiva dice Enrique 11: "e si batalla oviese de ser, sabe Dios que nos desplace de ello, empero nos no podemos excusar de poner nuestro cuerpo en defender estos regnos, a quien tan tenudos somos..." ${ }^{10}$. Mientras que el príncipe de Gales, después de ofrecerse como mediador entre los dos contendientes, dice lo siguiente; "E si queredes que se libre por batalla, sabe Dios que nos desplace mucho dello; empero no podemos excusar de ir con el dicho rey don Pedro, nuestro pariente, por el su regno" ".

La atenta lectura nos lleva a pensar que el cronista Ayala, al estilo de otros historiadores de la antigüedad grecolatina, estaba sirviéndose del conocido recurso de insertar cierta correspondiencia entre los personajes adversarios, a fin de conseguir una mayor fuerza narrativa y dar una mayor consistencia a la crónica. López de Ayala, sin embargo, no inventó esta correspondencia entre los dos principes. Las cartas originales, tres que no dos, entre el príncipe ingles y el castellano se han conservado, aunque en una copia ${ }^{12}$. El estudio realizado por José Luis Moure desde la óptica de la critica textual, nos lleva a la conclusión siguiente: Ayala, que conocía la citada correspondiencia entre los príncipes, realiza una elaboración personal de aquellas cartas; "no falseó los hechos, subrayó actitudes" "13, habida cuenta de que la redacción definitiva de la crónica es posterior al triunfo definitivo del sector enriqueño.

A pesar de todo lo que precede, el cronista, consciente de lo que va a hacer con los textos originales que tienen en su mesa de trabajo, inicia la narración histórica del cruce de cartas con las mismas palabras utilizadas por los notarios o escribanos a la hora de dar fe pública en sus documentos: «... e vinieron para Navarrete; e de alli envió el principe (inglés) al rey don Enrique un su Haraute con una carta, el tenor de la cual es este que se sigue" ${ }^{14}$; ahora conocemos que éste no es exactamente "el tenor» de las cartas, sino «el tenor" cronístico de una correspondencia entre dos principes.

Si la crítica textual ha llegado a la conclusión de que el canciller Ayala hizo su propia redacción de unas cartas escritas por otras personas, podemos entonces afirmar que el cronista, sirviéndose de una minuta, pre-

${ }^{10}$ Idem, ob. cit., pág. 351.

"Idem, ob. cit., pág. 350.

${ }_{12}$ Moure, José Luis, La correspondencia entre Enrique II y el principe de Gales en las versiones "vulgar" y "abreviada" de las Crónicas del canciller Ayala, en Incipit IV (1984) 9697.

${ }^{13}$ Idem, ob. cit., pág. 105.

${ }^{14}$ Lopez de Ayala, Pero, Crónicas, pág. 348. 
paró y expidió unos documentos cancillerescos, conforme a los criterios personales de los usos de cancillería. Desde nuestra óptica las cartas que aparecen en la crónica resultan un juicio de valor diplomático de los documentos, realizados por López de Ayala. En esta valoración se excluyen las cláusulas de la invocación, la de la salutación, que estaba en uno de los originales manejados por él ${ }^{15}$, y que en la carta de respuesta omite la notificación. Por esta via señala la menor importancia de las citadas cláusulas diplomáticas, al tiempo que resalta 10 imprescindible de aquellas otras de las que deja constancia en los documentos reelaborados.

En la crónica del rey Juan I nos encontramos con dos cartas procedentes del sultanato de Babilonia: una del propio sultán y otra de su alguazil y privado ${ }^{16}$. Sin duda alguna el cronista quería dejar constancia de la acción internacional realizada por su rey, cuestión esta que ahora no nos interesa.

Podemos pensar que estas dos cartas proceden realmente de la cancillería a la que López de Ayala las atribuye, o que no son más que un recurso cronístico para reforzar la figura de su rey. En cualquiera de los dos supuestos, intentaremos analizar desde nuestra óptica su estructura diplomática.

Las cartas presentan unas fórmulas de tratamiento ampulosas, barrocas y llenas, de una parte, de circunloquios y de otra, de soprendentes precisiones. En el primer caso, creemos que es debido a su conocimiento de la literatura árabe, pródiga en manifestaciones similares. Las precisiones pueden deberse a las noticias proporcionadas por viajeros que procedentes de aquellos paises visitaban la corte de uno y de otro reyno, los quales tendrian ocasión de dar a conocer los tratamientos adecuados en cada corte.

En la intitulación aparece el sultán sin enumeración de sus estados 0 dominios; en cambio, se enumeran todas las funciones y competencias como atributos de aquel principe: religiosas, de justicia, de conquistador... sin que falte el entroncamiento con sus más destacados antecesores en tal alta dignidad. En la dirección aparece el nombre de Juan, urey de Castilla e de los otros señorios que son con ella». Le sigue la salutación: "Dios ensalce su Estado, e guarde su salud e renueve su placer». En la exposición se explican los pasos seguidos por las cartas del rey de Castilla desde que llegaron a la corte del sultán: estas cartas fueron entregadas por los embajadores de Castilla al privado, éste las leyó al sultán

\footnotetext{
${ }^{15}$ Moure, José Luis, ob. cit., pág. 99.

${ }^{16}$ López de Arala, Pero, Crónicas, págs. 544-548.
} 
y fueron presentadas al consejo del rey de Babilonia; es muy sorprendente que los usos cancillerescos del sultanato, sean tan coincidentes con las maneras de la corte del rey castellano; pero asi nos lo narra el cronista. En el dispositivo se dice que, conocida la demanda del rey de Castilla, se ordenó que soltaran de la prisión al rey de Armenia y a su familia. El cronista traslada la datación al sistema de la era del César y en ningún caso aporta la suscripción de las cartas.

\subsection{El albalá}

En otros momentos el cronista López de Ayala narra algunos acontecimientos con connotaciones violentas en los que aparece un tipo documental llamado albalá. Asi, vemos como unos caballeros, junto con doña Maria, la madre del rey don Pedro, se habian hecho fuertes en la ciudad de Toro. Cuando vieron que ya no podian soportar la presión de las tropás reales, López de Ayala nos dice que "Ruy González de Castañeda, que estava con la reyna, avia traido su pleitesia secretamente antes de esto con el rey, e tenia una alvala suyo de perdón, e esforzábase en aquel perdón e dixo a la reyna: Señora, id al rey, ca lo no tenemos en al. E la reyna salió del alcazar e venía con ella la condesa doña Juana, mujer del conde don Enrique, e Rui González de Castañeda... e Rui González treia el alvalá del rey de perdón que le avia enviado antes de esto en la mano alta, diciendo que el rey ge lo enviara e que le perdonara por aquel alvalá; pero decía el rey, que el tiempo que él pusiera a Rui González de Castañeda para se venir a la su merced que era pasado e que ya no valía el alvalá... un escudero... llegó a Rui González de Castañeda e diole con un cuchillo por la garganta, e derribole, e matole" ${ }^{17}$.

De nuevo tenemos ocasión de unir el documento llamado albalá con una situación muy semejante a la anterior en la que se indica cómo el rey don Pedro habia mandado a Martín López de Córdoba, maestre de Calatrava, que diese muerte a unos caballeros, quien «dende algunos dias ... convidó a comer a los dichos don Gonzalo Ferrández e don Alonso Ferrández, e Diego Ferrández; e desque ovieron comido, mostroles un alvalá del rey en cómo le mandaba que les cortase las cabezas.... ${ }^{18}$.

En la crónica de Juan I de Castilla y durante las fiestas de su coronación en la ciudad de Burgos algunos judios "dixéronle que su merced fuese de les dar un alvalá para su alguazil, que si ellos le mostrasen e

17 Idem, pág. 164.

${ }^{18}$ Idem, pág. 389. 
dixesen que entre ellos era algún judio malsin, que le ficiese matar; ca decian que siempre ovieran ellos por costumbre de matar cualquier judio que era malsin. E el rey diógeles aquel alvalá. E los judios después que tovieron librado el alvalá del rey, ficieron luego ellos otros suyo, firmado en los nombres de aquellos que habian poder para ello, en que decian al alguazil que cumpliera el alvalá del rey... e como el alguazil vio el alvalá del rey e otro de los judios que regian o gobernaban las aljamas del regno, respondio que le placía cumplir el alvalá del rey.... ${ }^{19}$.

Parece que el albalá, un tipo documental del que siempre se reconoció su carácter económico, podia tener otro valor no vinculado a la economia, al menos en la mentalidad del cronista López de Ayala. Se asegura que la autoridad real es quien sustenta el valor del documento, del albalá; parece ser una autorización real que supone un corto periodo de duración o validez y que equivale a un mandato de rápida ejecución, como ocurre en los tres textos que anteceden.

Pero el albalá no es un documento de uso exclusivo de la cancillería real, aunque está vinculado a personas con autoridad. Hemos visto como los judios, una vez conseguido el albalá del rey, «ficieron luego ellos otro suyo firmado en los nombres de aquellos que habian poder para ello...", esto es, "los que regian e gobernaban las aljamas del regno" pueden emitir un albalá, que en este caso equivale a un mandato de ejecución contra un judio.

Don Juan Manuel en el Libro de los Estados, expone una definición del albalá bien distinta de la que precede. Para este autor el albalá tiene una vinculación directa con los asuntos económicos de la corte real o señorial, y en ningún momento hemos encontrado relación alguna de este documento con otra finalidad. Así podemos leer lo que sigue: "El despensero, a de conprar et de recabdar todas la viandas que son mester para casa del sennor, et él las a de partir e dar, tan bien las que se comen en palacio como las que se dan por raçiones. Et el despensero a de dar a los oficiales todo lo que an de despender cada uno en su ofiçio, et a de recabdar los alvalas de los ofiçiales de las viandas que reçiben, et dar él un alvala suyo de todo" ${ }^{20}$.

${ }^{19}$ ldem, págs. 511 y 512

20 Juan Manuel, Ob. y Edic. cit., vol. 1, pág. 407. 


\section{EL CANCILLER}

El lector de diplomas reales se acostumbra a ver la suscripción del canciller como un elemento de validación que aparece en multitud de documentos de origen cancilleresco y que no debe faltar nunca en los más solemnes. Por esta vía el canciller aparece al frente de esta alta institución real en todos los estudios realizados sobre las distintas cancillerías reales a partir del siglo xil. El canciller es el responsable de los sellos reales que penden de las "cartas" en pergamino o de aquellos otros sellos que se incrustan en el papel, los llamados sellos de placa ${ }^{20 b i s}$, a partir del momento en que el papel pasa a ser usado como soporte prioritario de los documentos regios.

Al canciller de la Edad Media se le vincula, a una gran “oficina» en la que se preparan y expiden los documentos a través de los cuales el rey reparte justicia entre los del reino.

Por si nuestra experiencia de atentos lectores de la documentación real de la Edad Media no fuera suficiente argumento, contamos con la aportación literaria de un escritor del siglo XIV, don Juan Manuel, quien presenta al canciller en los términos que siguen:

«... el más onrado ofiçio et el de mayor pro et que forçadamente a de saber lo más de la fazienda del sennor et de las sus poridades es el chançeller; que el ofiçio de chançeller es que él debe tener los sellos del sennor, et mandar fazer las cartas todas, tambien las mandaderas como las de ponimiento como las de guerra et de respuesta, et las que son para coger las rendas et los dineros de los sennores, et las de los enplazamientos et las de pago; et todas las cartas que fueren de fuerça deve tener registradas. Et en cabo, para vos lo ençerrar todo, conviene que todas las cartas que al sennor vinieren o el sennor enviare en qualquier manera, que todas vengan a mano et a poder del chançeller; ca, pues no puede ser carta sin ser seellada, no puede el sennor cosa mandar fazer que el chançeller no lo sepa, et a su mano et a su poder non aya de venir. Et por todas estas razones, porque forçadamente a de saber el chançeller toda la fazienda del sennor, conviene que sea su privado e su consejero... Otrosi, el chançeller debe levar la chançellería de sus cartas, de unas mas et de otras menos, segúnd son las mas aprovechosas para aquellos que las lievan, et segund es ordenado en aquella casa de aquel sennor cuyo chançeller fuere, del derecho que a de levar de ellas» ${ }^{21}$.

20bis Arribas Arranz, F., Sellos castellanos de placa. Valladolid, 195...

"Idem, ob. y Edic. cit., vol. 1, pág. 403. 
Don Juan Manuel coloca al canciller al frente de la cancilleria real, porque aquí tiene su origen, o señorial, porque también los señores destacados lo tenian, sin olvidar concluir que, debido a que el canciller es poseedor de toda la información que sale o entren a la "casa del señor», debe ser considerado además como privado, esto es, hombre de toda confianza y además consejero del señor a quien sirve.

Este planteamiento de que el canciller es el «jefe de la cancilleria»es muy conocido entre los paleógrafos y los historiadores y estudiosos de los temas de la época. Las obras literarias nos aportan otra visión distinta. A López de Ayala le importan sobre todo el aspecto político de los personajes que aparecen en el entorno más cercano al rey. En ningún momento presenta al canciller directamente implicado en el quehacer de la expedición documental, siempre aparece vinculado a las actividades politicas de la corte real, está en el consejo y no en la cancillería. Nada debe extrañarnos de la valoración hecha por ei cronista. Aparte de las exigencias del género literario, preocupado sobre todo por las cuestiones de largo alcance politico, el propio desarrollo de la cancilleria real le autoriza a presentar esta cara del canciller. Desde la Plena Edad Media toma fuerza la figura del protonotario. Este aparece como el responsable directo de la preparación y expedición documental; es el plenipotenciario del canciller ante los notarios reales. La existencia de esta figura permite que el canciller dedique sus esfuerzos a otros menesteres. Se le exime de la actividad directa en la cancilleria y a cambio asume responsabilidades politicas directas.

López de Ayala destaca la presencia de un canciller y de un canciller del sello de la poridad, responsabilidad que recae en personas distintas. La proximidad al rey beneficia al canciller del sello de la poridad; éste está más cerca del secreto. El cronista aplica el calificativo de “privado» al canciller del sello de la poridad, a lo largo de toda su crónica.

A nadie se le puede ocultar que el canciller es el primer responsable de la preparación y expedición de documentos y que está en el secreto de todos los asuntos de estado, situación que le coloca en un lugar de privilegio frente a los demás miembros de la corte real. Desde esta perspectiva nada podria parecer más lógico que el canciller figurara entre las primeras personas a las que habia que cambiar cuando la facción enriqueña consiguió descabalgar a la facción de los Padilla de la corte de Pedro I de Castilla el año 1353. Nos cuenta el cronista que «los caballeros aliados con la reyna Maria, madre del rey don Pedro, tiraron de los oficios a los que los tenian... determinaron que don Fernando (Infante de Aragón) fuese chançeller mayor e mandaron prender a Ferrand Sánchez de Valladolid fasta que diere los sellos... e el Infante levó consigo... a Ferrand 
Sánchez de Valladolid, que tenia los sellos e los avia de entregar al dicho Infante, que ordenaron que fuese chançeller mayor ${ }^{22}$.

Ferrand Sánchez de Valladolid, canciller real, obviamente, no llevaba consigo los sellos reales, sino que éstos, a tenor del texto, estaban custodiados por el personal de la cancilleria, como antes señalamos, por el notario mayor, que no debia de estar en ese momento entre los grandes del reino que formalizaron los nuevos nombramientos. Por esta via se distingue, nuevamente, al canciller por un lado y al responsable efectivo de la cancilleria, esto es, son dos personas distintas, con dos cometidos diferentes: el canciller vinculado a lo politico y el notario mayor que ostenta la responsabilidad directa en la cancilleria real. En la nueva corte estructurada en la ciudad de Toro aparece de nuevo esta orientación, ya que, el infante de Aragón, hombre de la politica, es nombrado canciller.

Pero el rey habia cedido a la presión enriqueña de forma circunstancial y estaba decidido a recuperar su libertad de acción. Pedro I salió de Toro y se fue para Segovia dejando en aquella ciudad su cancilleria. Una vez en Segovia, nos dice el cronista que "envió sus cartas a la reyna doña Maria, su madre, e a los otros que y eran, que le enviasen su chançillería e sus sellos; e si non, que sopiesen que él podria bien aver plata e fierro para facer otros sellos. E los que estaban en Toro enviáronle sus sellos, e mandaron a los chancilleres e notarios que se fuesen para él; e asi lo ficieron" ${ }^{23}$.

Este relato destaca la importancia concedida por López de Ayala a la cancillería, especialmente, a los sellos reales en cuanto emblema de la institución; al mismo tiempo delata la existencia de una persona encargada de velar por el sello y otra distinta para guardar la matriz. El rey tiene la matriz y le basta con "plata e fierro" para hacer unos sellos nuevos.

\section{LA DATACIÓN}

López de Ayala no pasa por alto la cuestión del sistema de datación que debia usarse, tanto en los documentos emanados de la cancilleria real, como los preparados por cualquier otra instancia o institución que pudiera estar implicada en la expedición de las escrituras, sin exceptuar

\footnotetext{
22 Lopez de Ayala, Ob. cit., págs. 135-136.

3 ldem, ob. cit., pág. 138.
} 
las obras de carácter histórico que debian fijar los acontecimientos en el tiempo. El cronista en su obra reconoce la existencia de las tres culturas, tanto en la sociedad cuya historia nos narra, como en aquella a la que iba destinada su obra: la cristiana, la judia y la mohometana. Quiere facilitar a cada uno la fijación cronológica de los acontecimientos, y para ello utiliza el modo de datación usado por cada uno de los grupos sociales.

Dejamos a un lado otros aspectos referentes a la cronologia incluidos por López de Ayala en su crónica ${ }^{24}$ y nos detenemos sólamente en la parte correspondiente a la determinación del origen y subsiguiente explicación del sistema de datación por la llamada "era hispánica» que el cronista llama "la era del Cesar, segúnd costumbre de España» y añade:

“E la razón porque es esta era del Cesar es, porque este emperador que ovo nombre octaviano Cesar Augusto, sobrino del emperador julio Cesar, hizo paz con todas las gentes del mundo, e púsolas so su señorio, e fueron sus subditos, e fue monarca que es dicho en latin señor de todo el mundo. E fue dicho en su tiempo era, e fincó en costumbre en España de ser asi llamados los tiempos, por quanto el dicho Octaviano Cesar Augusto ordenó que fasta ciertos años todos los de sus señorios se veniesen a escribir, por saber cuántos eran, cada uno en su comarca, e que diese cada uno un dinero en señal de conoscimiento de señorio, que todo el mundo le obedescia. E porque en latin es llamado el cobre de que hacen moneda oes, oeris, fincó aquel nombre era, que quiere decir el año en que Cesar mandó escrebir e levar moneda de cada uno de los súbditos, por el conoscimiento de la obediencia que le ficieron. E porque España era una provincia de las que asi le obedescieron, fincó con esta costumbre que antiguamente ovieron de llamarla era de Cesar. ${ }^{25}$.

Más adelante en la narración del reinado de Juan 11 , dice que este rey en las Cortes en Segovia "fizo muchas leyes e ordenamientos, de las qua-

\footnotetext{
${ }^{24}$ Idem, ob. cit., págs. 26 y ss., donde expone lo referente a la datación por el “año de la Encarnación" o por el de la "Navidad" e incluye también la datación por el sistema de la «indición» usado por la "corte del Papa" con la explicación siguiente: "E debedes saber que este cuento de la indición descendió de los romanos." Narra en extenso las razones del establecimiento de esta fórmula cronológica y concluye dando el sistema de resolución de la indición con las siguientes palabras: «E si quisiéredes saber la indición en que anda, toma el año en que nasció Jesuchristo, e sabe en qué número anda, e añade más tres años. e pártelos todos por quince, e lo que sobre es la indición de aquel año; e si non fincare cosa del cuento, será la indición en quince. E la razón porque se añade tres sobre el cuento del año en que nuestro Señor Jesuchristo nasció es, porque él nasció de la Bienaventura Virgen Sancta Maria en la tercera indición de los romanos".

${ }^{25}$ Idem, ob. cit., págs. 25 y ss.
} 
les pocas se guardaron; salvo una ley que fizo, en que mandó que se non pusiese en las escripturas la era del Cesar, salvo el año del nascimiento de nuestro Salvador Jesuchristo, que comenzó este año dende la navidad en adelante, e fue año del Señor de mil e trescientos e ochenta e tres" ${ }^{26}$.

\section{LOS COPISTAS Y LOS ESCRIBANOS}

Con toda seguridad se enfadarian los escribanos (nos referimos a los escribanos públicos) si les mezclamos en el asunto que nos va a ocupar en este momento. Deberiamos hablar de amanuenses o copistas, actividad esta no ligada directamente al oficio de la fe pública otorgada por aquellos, pero no totalmente desvinculada de su actividad, razón por la que nos atrevemos a usar aquel título para este capitulo.

En el prólogo de la obra El Conde Lucanor, de Juan Manuel, leemos las preventivas palabras que siguen:

"E porque don Johan vio e sabe que en los libros contesçe muchos yerros en los trasladar, porque las letras semejan unas a otras, cuydando por la una letra que es otra, en escriuiendolo, mudasse toda la razón et por aventura confondesse, et los que despues fallan aquello escripto, ponen la culpa al que fizo el libro; et porque don Johan se reçeló desto, ruega a los que leyeren qualquier libro que fuere trasladado del que él compuso, o de los libros que él fizo, que si fallaren alguna palabra mal puesta, que non pongan la culpa a él, fasta que vean el libro mismo que don Johan fizo, que es emendado, en muchos lugares, de su letra... Et los libros que él fizo... estan en el monesterio de los frayles predicadoies que él fizo en Peñafiel. Pero desque vieren los libros que él fizo, por las menguas que en ellos fallaren, non pongan la culpa a la su entençión, mas póngala a la mengua del su entendimiento, porque se atrevió a se entremeter a fablar en tales cosas. Pero Dios sabe que lo fizo por entençión que se aprovechassen de lo que él diría las gentes que non

\footnotetext{
${ }^{26}$ VIVES, José, Inscripciones cristianas de la España romana y visigoda. Madrid, CSIC, 1969. (reedición), págs. 177-185; IDEM, Manual de cronologia española y universal. Madrid, CSIC, 1953, págs. 10 y ss. Para Vives esta explicación de la «era del Cesar», sin rechazarla, se corresponde con la aceptada por San Isidoro y otros Padres españoles. Defiende Vives que la datación por el sistema de la era, es tipicamente española y de origen no esclarecido. Añade que "la era hispánica es continuación de la que podríamos llamar era astúrica. En esta provincia, pues, hay que buscar el origen de la era hispánica, aunque no se pueda establecer cuál fuera el fundamento o acontecimiento histórico en que se apoya". El punto de partida para estas conclusiones, es un estudio pormenorizado de un conjunto de inscripciones de origen cántabro-astur de la época de los visigodos.
} 
fuessen muy letrados nin muy sabidores. Et por ende, fizo todos los sus libros en romançe et esto es sennal çierto que los fizo para los legos et de non muy gran saber como lo él es" ${ }^{2 ?}$.

El copista, el amanuense o el escriba, por su propia voluntad y en salvaguarda de los intereses propios o de Don Juan Manuel, redacta una nota preventiva contra posibles falsificaciones atribuidas, no al autor, sino a errores gráficos y lo hace en tercera persona. Tampoco quiere herir a sus compañeros de oficio y achaca "los yerros en los trasladar" a que «las letras semejan unas a otras" liberando a los amanuenses o copistas de la ignorancia y falta de destreza que la acusación pudiera implicar, dejándolo todo en un simple despiste.

Pero don Juan Manuel, en primera persona, en el prólogo a su obra Libro del Cauallero et del Escudero, expone esta misma idea en la forma que sigue:

«Et recelando yo, don Johan, que por razon que non se podrá escusar, que los libros que yo he fecho non se hayan de trasladar muchas vezes; et porque yo he visto que en el trasladar acaeçe muchas vezes, lo vno por desentendimiento de scriuano, o porque las letras semejan unas a otras, que en trasladando el libro porná una razón por otra, en guisa que muda toda la entençión et toda la sentençia et será traydo el que la fizo non aviendo y culpa... ${ }^{28}$.

No es una cuestión menor afirmar que "los scriuanos", asi llama el autor a los copistas, por su torpeza pueden cambiar el sentido del texto. La afirmación procede de alguien que se dedica a escribir libros y que ha padecido esta desagradable experiencia. Estos errores se deben, no a que escriban mal lo que copian, sino a "desentendimiento", esto es, a falta de entendimiento o preparación, a que los copistas apenas si dominan el arte y la lectura ya que confunden unas letras con otras, y una vez producida ésta situación, no son capaces de entender la falta de sentido de lo que han copiado. A falta de una explicación más amplia en el texto que precede acerca de las razones por las que esta circunstancia se produce, intentaremos nosotros llegar a un hipotético razonamiento.

\footnotetext{
${ }^{27}$ Juan Manuel, El conde Lucanor, Edición de Blecua, José Manuel, Don Juan Manuel, Edit. Gredos, 1983, V. II, pág. 23.

${ }^{28}$ Juan Manuel, Libro del Cauallero et del Escudero, Edición de Blecua, José Manuel, Don Juan Manuel, Edit. Gredos 1982, V. I, pág. 32
} 
El mismo Don Juan Manuel en su obra El libro de los Estados ${ }^{29}$, al tratar de la educación del infante heredero dice:

"Et desque pasaren de çinco años adelante, deuen començar poco a poco a les mostrar leer, pero con falago e sin premia. Et este leer deue ser tanto, a lo menos, fasta que sepan hablar e entender latín. Et despues deuen fazer quanto pudieren porque tomen plazer en leer las coronicas de los grandes fechos e de las grandes conquistas et de los fechos de armas et de caballerias que acaesçieron...".

El invento de la escritura es posterior al del lenguaje, aquel se aprende por vía de la educación y éste por vía natural, en ambos casos por el camino de la repetición e imitación. El aprendizaje de la escritura es el paradigma del proceso de imitación y de repetición; el niño sigue los trazos de las letras, se conforma al modelo propuesto.

La ortografia latina, a pesar de su progreso a través del tiempo, no llega jamás al grado de uniformidad que se le supone en nuestros dias, aspecto éste muy a tener en cuenta en el caso que nos ocupa. Los escribanos, según el esquema educativo propuesto por don Juan Manuel, aprenderian el latin, pero un latin al que faltaba la uniformidad, no sólo en el lenguaje, propio y peculiar para cada una de las provincias que fueron latinas, sino también en la grafía. La uniformidad gráfica del latín supondria una uniformidad oral automática; creer que cada letra corresponde a un sonido bien preciso y siempre el mismo, es una aventura falaz. El latin ha presentado toda una gama de variaciones según el lugar, la clase social dónde y por quién se pronuncia y también las distintas épocas ${ }^{30}$.

Es posible pensar que la educación latina de los copistas a los que alude don Juan Manuel no fuera tan buena como era de desear ${ }^{31}$. Las dificultades internas del propio latin, no uniformado para la escritura, más las oscilaciones mentales del amanuense, entre un latín mal conocido y un romance castellano en vías de fijación definitiva, pudieron dar como resultado aquellos "yerros en el trasladar".

Cabria preguntarse todavia a qué grupo de escribanos se refiere el autor. Se nos dice que don Juan Manuel entregó los originales, corregi-

29 Juan Manuel, Libro de los Estados, Edición de Blecua, José Manuel, Don Juan Manuel, Edit. Gredos, V. I, pág. 324.

${ }^{30}$ Desbordes, F., ldèes romaines sur L'ecriture. Presses. Universitaries de Lille 1990.

${ }^{31}$ Villimer Llamazares, S., Estudios de latín medieval. Documentación de la cancilleria castellana: siglos $x / v$ y $x \mathrm{~V}$. Valladolid 1977. 
dos de su puño y letra, en el monasterio de Peñafiel, por él fundado. Nos inclinamos a pensar que si alli estaban los originales, las copias podian salir del mismo lugar, o al menos, de los escritorios monásticos, lo que situaria a los copistas en el "Estado de la clerecía» por utilizar el mismo lenguaje que el autor nos trasmite. Que entre sus contemporáneos, los aspirantes a clérigos, debian estudiar el latín, es de todos conocido; otra cosa bien distinta es el grado de aprendizaje del latín al que llegarán la mayoria de aquellas personas que dedicaban su vida a la clerecia. Por otra parte, se nos dice que el libro está escrito para los "legos" y en el lenguaje de los legos. Tendriamos esta situación: unos clérigos que estudian latin, que leen textos latinos en sus rezos y en sus bibliotecas, dedican algún tiempo a copiar libros en romance; leen unos textos latinos sin uniformidad gráfica (letra visigótico-mozárabe, carolina, gótica) y escriben textos en romance con escasa uniformidad gráfica. Por añadidura, nada se nos indica sobre la forma de realizar la copia. Podía realizarla una sola persona, copiando directamente del ejemplar que tenia delante, o con la ayuda de otra persona, esto es, al dictado, lo que implicaria copiar palabras pronunciadas por otra persona, añadiendo a ello las dificultades provenientes de la distintas formas individuales de pronunciación.

Podria el autor basar su desconfianza en la creencia de que los escribanos a los que se refiere copian documentos y códices, escritos en letra visigótica o mozárabe, ya en total desuso y posiblemente apenas conocida entre sus contemporáneos. Podemos añadir, en descargo de los copistas, que los códices de su época están escritos en letra gótica, cuyos nexos imbrican unas letras en otras, lo que crea serias dificultades de lectura para personas no expertas. En cualquier caso siempre nos encontrariamos con lo mismo: los copistas coetáneos de don Juan Manuel, no están preparados para ejercer su oficio con total acierto y no cuentan con el favor del citado autor, antes al contrario, prefiriria que no ejercieran su oficio con las obras por él escritas.

La denuncia de don Juan Manuel no implica una acusación de falsificación intencionada. Los copistas en general, dice, cometen errores por confundir unas letras con otras debido a su ignorancia, lo que no implica culpabilidad. En el terreno de la hipótesis que no podemos ni pensar como cierta debido a los controles de la documentación, la situación adquiere mayor importancia si lo trasladamos a otros centros de preparación y expedición de documentos, en los que los errores de este tipo pueden variar el sentido de un diploma y por lo mismo dar ocasión a expedir un documento falso, por ignorancia si, pero falso. Esta situación podría darse en una cancillería, real o señorial, en el escritorio de un 
monasterio, donde se preparan y expiden tantos documentos, o en una escribanía concejil. En todos estos lugares existen los "concertadores".

Con independencia de lo dicho sobre los conocidos comunmente entre nosotros como los copistas, los escribanos públicos o notarios, aparecen en muchas ocasiones a lo largo de las crónicas en el ejercicio de las funciones que les son propias, es decir, la de dar fe pública. No juzgamos de interés, en esta ocasión, hacer una prolongada exposición sobre este oficio, pero no podemos dejar a un lado a los escribanos públicos, porque su presencia en las crónicas revela aspectos no muy conocidos en el desarrollo tanto de su actividad, como de su personalidad e implicaciones sociales.

Don Enrique se ha proclamado rey en Calahorra y Pedro I, que estaba en Burgos, salió de ésta ciudad. Los burgaleses pidieron al rey que no les abandonase que le darian todo lo que fuere menester, «e que de este requerimiento que le hacian pedian a los escribanos que y estaban que les diesen instrumentos signados". A estos escribanos se les pide simplemente que den fe pública de aquello de lo que son testigos ${ }^{32}$.

Los escribanos públicos pueden estar en la acción política y sufrir sus consecuencias. En una ocasión, en Burgos «prendieron a tres omes de la cibdad que decian al uno Pero Fernández de Medina, e al otro Alfonso Fernández, escribano, e al otro Alfonso García de Camargo, e por sobrenombre le decian el izquierdo" ${ }^{33}$. En otra ocasión, el rey Pedro de Castilla y el rey Pedro de Portugal, llegaron a un acuerdo. Cada uno de ellos entregaria al otro los caballeros y las personas que habian huido del reino del que eran naturales. En cumplimiento del pacto cfueron entregados al rey de Portogal Pero Cuello, e un escribano, los cuales fueron muertos en Portogal" ${ }^{34}$.

A veces sirven de brazo ejecutor. Alfonso Fernández de Olmedo, escribano de la reina doña María, por mandato de ésta, "mató a la dicha doña Leonor (de Guzmán, mujer del rey Alfonso XI) en el alcazar de Talavera» ${ }^{35}$.

\section{LA VALIDACION}

La prisión del caballero bretón mosen Beltrán de Claquin, uno de los que entraron en Castilla con el rey don Enrique, sirve de ocasión al cro-

\footnotetext{
López de Ayala, Pero, Crónicas, pág. 315

33 Idem, ob. cit., pág. 34.

${ }^{34}$ Idem, ob. cit, pág. 246

${ }^{35}$ Idem, Ob. cit, pág. 30.
} 
nista para explicar por extenso el acontecimiento de la liberación del citado caballero. Mosen Beltrán de Claquín era tan grande y orgulloso como pobre caballero. Decidida su liberación, se le dio ocasión a que él mismo fijara la cantidad que debía pagar para ser puesto en libertad. Se autovaloró en cien mil francos de oro, cantidad que no poseía. Pero tenía crédito suficiente entre otros caballeros bretones, de forma que les escribió una carta en la que les pedia "porque él fuera cierto de sus voluntades quales eran, que cada uno de ellos le enviara un su escudero que llevara su sello e poder para le obligar en la quantia que monsén Beltrán quisiese e al plazo que pusiese" ${ }^{36}$.

Para su mentalidad, cosa que también sorprendía al cronista ya que resalta el acontecimiento con toda serie de detalles, no era necesaria la presencia y la consiguiente firma de los caballeros bretones; bastaba con la aposición del sello para validar aquella fianza "porque en Francia y en Inglaterra la mayor obligación que caballero e ome de linaje puede dar es su sello; ca dicen, que poner ome su nonbre es asaz, pero en el sello va el nonbre e las armas, que son horira de caballero" ${ }^{37}$.

Para el cronista y sus contemporáneos, la aposición del sello como signo de validación documental, es importante, pero tienen una importancia menor. López de Ayala se complace en dedicar unas cuantas lineas a narrar no sólo el acontecimiento y la idea de la solidaridad que trasluce, sino también la reconocida fuerza de la validación que el sello tiene para los bretones.

La nobleza castellana no concedia tanta importancia al sello como medio de validación. Sin embargo, ya hemos visto más arriba la reacción del rey Pedro I cuando, atrapado por el sector enriqueño, se va de Toro dejando alli la cancillería y el sello real y como reclama éste con tono amenazador.

Durante la minoria de Enrique III, el reino de Castilla proyecta alcanzar una paz duradera con el reino de Portugal. La embajada castellana la componen Don Juan Serrano, obispo de Sigüenza, Pero López de Ayala, el cronista a quien pertenece esta narración, y el doctor Antón Sánchez, oidor. Cerrada la negociación en tierras portuguesas, nuestros embajadores, no muy contentos con los resultados alcanzados, demandan un mandato expreso del rey y de su consejo de regencia, y piden que "lo pusieran por escrito, firmado del nombre del rey e de los sus tutores de sus nombres e seellado con el sello del rey, e signado del escribano de

${ }^{36}$ Idem, Ob. cit., pág. 364.
${ }^{37}$ Idem. 
su cámara ${ }^{38}$. Los embajadores piden la firma del rey, la de los regentes y la del secretario de cámara quien además de levantar acta de la reunión del consejo de regencia, con su firma convierte al diploma en documento salido de la cancilleria real. No se ignora el sello y su valor autentificador, pero se insiste en la necesidad de que se aporten todas las firmas de las personas implicadas en la decisión. Los propios regentes en el quehacer diario de la actividad politica, piden continuamente que los escribanos levanten acta de lo hablado, de lo mandado o de lo hecho, "para que cuando el rey sea mayor de edad" pueda conocer todo lo realizado.

\section{CURIOSIDADES}

Debió tener Don Juan Manuel dos aficiones de profundas raices: la lectura y la caza. A la hora de exponer el esquema educativo para el príncipe heredero insiste de forma continuada en la necesidad de leer y en la necesidad de caminar y cazar, sin que ello implique el abandono de otros aspectos. Hasta tal punto la lectura, tanto en latin como en árabe, y la caza iban juntas en su vida que imbrica la una en la otra de la forma más sencilla.

En el Libro de la Caza ${ }^{39}$, trata Don Juan Manuel de los distintos tipos de animales. Al hablar de los halcones y de los "girifaltes» distingue, entre otros, los blancos de los pardos por el color de su plumaje. Dice de los blancos: "ca otros ay que son muy blancos, mas an por las espaldas unas pintas como manera de letras moriscas muy prietas et por los pechos algunas pintas pocas muy prietas. Et como quiera que non los tienen por tan nobles como los blancos del todo, esos et estos son los mejores, et llámanlos letrados".

Pero no queda ahí la cosa. Un instrumento de escritura aparte de servit para trazar las letras, puede tener alguna otra utilidad. Hablando de las enfermedades de las aves de caza, de los halcones y de los girifaltes, dice Don Juan Manuel: «Desque las güermezes apareçieren en la lengua o en las quixadas o en el paladar o doquier que las tengan, deuen gelos sacar con una pennola tajada en manera que quiera semejar a la pennola con que escriben" ${ }^{40}$.

\footnotetext{
38 Ibidem, pág. 813.

39 Juan Manuel, Libro de la caza, Edición de Blecua, José Manuel, Don Juan Manuel, Edit. Gredos 1982, vol. I, pág. 529.

40 lbidem, pág. 531.
} 